\title{
A INSEGURANÇA MARÍTIMA NA ÁFRICA SUBSARIANA E OS SEUS REFLEXOS NA ECONOMIA DOS ESTADOS
}

\author{
Damião Fernandes Capitão Ginga ${ }^{1}$
}

\section{Introdução}

Os problemas de insegurança no continente Africano são mais antigos que a sua constituição enquanto "Unidade Política", formada por Estados soberanos, na medida em que desde cedo enfrentou obstáculos ao nível da sua integridade territorial, devido a um conjunto de fatores, muitas vezes, externos aos interesses africanos, onde se destacam, as conquistas promovidas por vários povos ao longo de vários séculos, as ocupações levadas a cabo pelas grandes potências durante o século XIX e, nas últimas décadas, a cobiça de vários atores da Política Internacional pelos espaços africanos (Ginga 20I4).

Assim, o aumento da importância geopolítica das regiões africanas, nomeadamente as regiões Ocidental e Oriental, tem despertado um maior interesse político e econômico das principais potências mundiais, mormente pelo seu posicionamento no eixo das principais rotas do comércio mundial e pelo potencial em recursos naturais, o que reforça o valor geoestratégico do continente (Beny 2007). Com efeito, embora a relevância dos oceanos no quadro das dinâmicas internacionais seja inquestionável, as ameaças que nele afluem muitas vezes parecem ser menos precisas, pelo que durante várias décadas, a abordagem securitária continental teve um foco predominantemente territorial, uma vez que o principal objetivo dos Estados africanos era o asseguramento das questões consideradas "prioritárias" (fronteiras terrestres), em detrimento de outras questões consideradas “acessórias”, como a segurança marítima².

I Professor Auxiliar Convidado do Instituto Superior de Relações Internacionais Venâncio de Moura, Angola.

2 Ademais e acordo com Therezinha de Castro (I999, 253), "o destino geopolítico de África durante séculos foi de viver atrás da barreira do litoral”, pelo que se infere que a história do continente Berço, por questões de identidade cultural, é marcada pela cultura da territorialidade. 
Como resultado, a insegurança nestes espaços continua a fragilizar a soberania e estabilidade local, impedindo o harmonioso e contínuo desenvolvimento das nações, num cenário marcado por mudanças contínuas geradoras de incertezas, que por vezes evoluem para crises múltiplas, associadas a problemas de vária ordem ${ }^{3}$ (Keohane 2002). Este contexto, com quadrantes positivos e negativos, tem pesado sobre a evolução política e no desenvolvimento dos Estados africanos, num panorama em que as mais frequentes e principais ameaças à segurança marítima no continente, se têm materializado através de ações de terrorismo marítimo; da pirataria; da pesca ilegal não reportada e não regulada (INN); do contrabando de armas, pessoas e bens; da imigração clandestina; dos derrames de substâncias perigosas; da depredação dos recursos marinhos; entre outras manifestações do crime organizado ${ }^{4}$.

$\mathrm{Na}$ realidade, a segurança marítima em África tem também implicações diretas para o resto do mundo, porquanto, em 2007, cerca de $60 \%$ da cocaína no mercado europeu (avaliada em I,8 mil milhões de USD) transitara pela África Ocidental. Grande parte dos carregamentos do narcotráfico chega à África em navios de carga, sendo depois transferida em pequenas embarcações para a sua expedição para outros continentes. Neste particular, dos 775 milhões de USD em cigarros do contrabando e os cerca de 438 milhões de USD em medicamentos contrafeitos para a malária, que passam pela África Ocidental, são transportados por Mar. Associado a tudo isto, estima-se também que a pesca INN, transportada preferencialmente por navios comerciais europeus e asiáticos, custe à África subsaariana mais de I. ○०० milhões de USD anualmente (Vogel 2009).

Portanto, a abordagem aqui apresentada visa aprofundar o debate sobre as questões marítimas no seio dos principais interessados em temáticas que versam a causa africana em geral, e as questões da maritimidade em particular, servindo assim de mais um elemento de análise sobre o estado de quase abandono das fronteiras e espaços marítimos dos países africanos, dado ser evidente a postura letárgica das autoridades africanas, no que concerne às questões ligadas aos oceanos. Abordar a insegurança marítima africana não é apenas uma reflexão sociopolítica sobre os fatos, mas também uma

3 A saber: de natureza econômica social e política; de extremismos e fundamentalismos; de reformas inapropriadas nas estruturas do Estado; da contínua violação dos direitos humanos e da coletividade; da proliferação da criminalidade organizada; entre outros fenómenos geradores de novas ameaças sistémicas e erosivas, que marcam a "Nova Ordem Mundial".

4 Estas tendem a se alastrar, quer pela permeabilidade das fronteiras desses Estados, com especial referência aos Estados da região subsariana, como pela falta de capacidade em exercer a autoridade do Estado nos seus espaços marítimos (Ginga 20I4). 
visão economicista e de Desenvolvimento Humano, na medida em que no presente ensaio cientifico fazemos uma abordagem transversal às questões da insegurança marítima no continente, com um maior enfoque à região Ocidental (Golfo da Guiné), elencando os principais desafios e apontando algumas medidas a adotar, tendo em vista a melhoria no paradigma. Importará por isso perceber, qual o papel dos Estados africanos, enquanto garantes da segurança e defesa marítimas, e promotores do desenvolvimento sustentável no continente, bem como que outras abordagens transversais ao continente podem ajudar a criar um regime de cooperação marítima para toda a África?

\section{Dilema da Insegurança Marítima}

A situação geopolítica do continente Africano é muito marcada pelo "autobloqueio geográfico", sendo que cerca de I/3 do seu território encontrase bloqueado no acesso aos oceanos pelo restante $2 / 3$, dando a imagem de um continente dentro de outro. Conforme refere Políbio de Almeida (I994, II9), África é um mundo que pelas suas particularidades geopolíticas está intimamente ligado ao mundo marítimo, em que as suas potencialidades em recursos minerais, a componente oceânica de toda a África subsariana, entre outros fatores relevantes no quadro geopolítico e geoestratégico global, conferem um lugar prestigiado aos seus Estados. Desde logo, quando abordam-se assuntos concernentes ao desenvolvimento do continente Africano ou à segurança das fronteiras dos seus países, não se deve ignorar a vertente marítima, porquanto a maior parte dos Estados africanos são nações litorâneas.

O continente Africano atravessa atualmente a terceira fase da chamada "Scramble for África", motivada por razões geopolíticas, geoeconômicas e geoestratégicas, fazendo com que as maiores potências internacionais estejam cada vez mais atentas às dinâmicas nesta região; no sentido em que os recursos minerais e energéticos ocupam um lugar central neste novo posicionamento (Abegunrin 2009). Estas facilidades continentais, associadas às fragilidades estruturais e sociopolíticas, intensificam o interesse que as regiões africanas despertam para os atores externos, tornando-as "apetecíveis" para as principais potências internacionais, nomeadamente para aquelas interessadas na exploração dos seus recursos naturais, e para os principais agentes do crime organizado.

No quadro das fragilidades, destacam-se a fraca capacidade de guarnecer as fronteiras marítimas e os poucos recursos disponíveis para o exercício permanentemente da autoridade do Estado no mar, onde se incluem 
os grandes lagos, rios e vias navegáveis interiores. Portanto, o espaço marítimo e as fronteiras marítimas incluem-se neste sistema cada vez mais permeável e difuso, porquanto a extensa linha costeira dos Estados da região subsariana de cerca de $30.725 \mathrm{~km}$, enfraquece mais ainda a sua condição (Otto 2020). Esta é a face de um continente que tem sido fragilizado pela insegurança marítima, com consequências ao nível do desenvolvimento econômico, onde os países com fracas estruturas enfraquecem muito mais a condição continental.

Estas fragilidades, associadas aos baixos índices de integração e cooperação ao nível regional, têm resultado em entraves no que se refere ao controlo das fronteiras marítimas, seja do mar territorial e da Zona Econômica Exclusiva (ZEE), como das águas internacionais onde estão incluídas as rotas marítimas que por aí passam, o que tem repercutido num atraso ao desenvolvimento dos seus Estados. Neste entendimento, o Presidente dos Camarões, Paul Biya, durante a Cimeira de Chefes de Estado e de governo sobre a Segurança Marítima em Yaoundé (24-25 junho, 20I3), defendeu que a insegurança marítima "poses a serious threat to the peace and stability of African States (as) it undermines the people's development and well-being" (UA 20I3, 2).

$\mathrm{Na}$ verdade, nos últimos anos, o continente que havia evitado o terrorismo e o extremismo religioso por longas décadas transformou-se no novo foco da radicalização marítima, na medida em que "[...] the competitive advantage generated by the region's weak state capacity and rule oflaw, the existence of well-developed smuggling networks, and its geographic location all heighten its appeal to drug trafficking cartels and criminal gangs" (Marc, Verjee e Mogaka $2015,33)$. Neste quadro, as águas do continente, nomeadamente das regiões do Golfo da Guiné (GG) e do Golfo de Adem (GA), têm sido alvos de uma multiplicidade de atividades ilícitas, que minam a segurança marítima e impedem o desenvolvimento econômico.

Como resultado, nos últimos anos o combate à insegurança marítima tem ocupado um lugar central nas principais agendas de desenvolvimento dos Estados africanos, ainda que esta consciência seja pouco materializada pelas dinâmicas políticas aí desenvolvidas. Indubitavelmente, as questões sobre a insegurança marítima no continente Africano, que são transversais a todas suas regiões, são de caráter multidimensional, pelo que por questões de racionalidade de espaço não seria possível analisá-las no âmbito deste artigo, no sentido em que a abordagem centra-se mais detalhadamente ao contexto de insegurança marítima na costa ocidental da região da África Subsariana (GG). Com efeito e reevocando o lado negativo da globalização, as ligações transatlânticas que passam pela costa ocidental do continente, associadas às facilidades em termos de recursos naturais, fazem da região do GG uma autoestrada da criminalidade no mar, vulgarmente denominada 
como "Highway 10", atraindo todo tipo de interesses e incluindo atividades ilícitas e ilegais como a pirataria, o narcotráfico, o contrabando de armas e diamantes, a pesca INN, a imigração clandestina, o terrorismo, a deposição de substâncias nocivas ao ambiente marinho, entre outras atividades originadas pela avidez de muitos países, organizações e grupos (Mugridge 20I0).

Com doze Estados costeiros, os oceanos têm um valor econômico incomensurável para a região do GG, representando, desde logo, um dos maiores ativos para as suas economias. Contudo, na maior parte dos casos, este potencial econômico continua por explorar, sobretudo devido às inúmeras vulnerabilidades internas, como a fraca autoridade estatal, os escassos recursos existentes e, consequentemente, o deficiente patrulhamento dos espaços marítimos (Abegunrin 2009). Esta região, marcada pela guerra, instabilidade sociopolítica e pobreza extrema, confrontada com a porosidade das suas fronteiras e a extensa linha costeira, deficientemente vigiadas, tem enfrentado várias atividades ilegais, onde se destaca: a pirataria; o terrorismo marítimo; a pesca INN; o narcotráfico; o contrabando de pessoas, armamentos, medicamentos e de diamantes; o roubo de petróleo e de carga; os derrames de substâncias; entre outras manifestações da criminalidade no mar.

A "pirataria marítima” tem representado um dos principais "vírus" para o Domínio Marítimo Africano (DMA) e um grande negócio para o mundo do crime organizado, concentrando-se em regiões de considerável importância geoestratégica. Se antigamente a pirataria era fundamentalmente usada como ferramenta para as nações expandirem o seu domínio no mar, hoje, a pirataria moderna tem um efeito contrário no poder dos Estados, contribuindo para o enfraquecimento das suas estruturas e fragilizando o controlo dos seus espaços (Coudenhove-Kalergi I959). O século XX ficou marcado pela baixa incidência de ataques de pirataria na região, porém, nos últimos anos, assistese a um recrudescimento do fenómeno, na medida em que até ao final da Ia década do século XXI, a África Oriental representava o epicentro do fenómeno a nível global; sendo que de acordo com o relatório anual do "American One Earth Future Foundation", até ao final de junho do ano 20I2, a pirataria rendeu cerca de I6o milhões USD a favor dos piratas, tendo custado à economia mundial cerca de 7 mil milhões de USD.

O negócio tem sido fundamentalmente alimentado pelo roubo de carga e pelo resgate de pessoas e bens, com um impacto econômico direto na estabilidade e desenvolvimento regional (Onuoha 20I2, 2, Miah 20I2). $\mathrm{Na}$ atualidade e de acordo com os relatórios anuais do International Maritime Bureau (IMB), 20I6, 20I7, 2018 e 20I9, nos últimos anos este fenómeno tomou uma dimensão preocupante, especialmente na costa ocidental do continente, sendo já considerada o "New Pirate Hot Spot" (Novo Epicentro 
da Pirataria), porquanto os piratas têm desenvolvido o seu modo de atuação e os respetivos instrumentos, o que lhes tem permitido alcançar maiores distâncias (IMB 2020).

Todavia, os dados apresentados pelo relatório do Oceans Beyond Piracy/ American One Earth Future Foundation de 2017, descreve que "the number of seafarers affected by piracy and armed robbery in 2017 decreased slightly from 2016 [...] in total, 1,726 seafarers were affected by piracy and armed robbery in 2017 in West African waters, compared to 1,921 in 2016" (AOEFF 2018, I2), embora que pela primeira vez em dois anos consecutivos, observaram-se incidentes de sequestro no mar na região5. Destarte, regra geral, enquanto a pirataria no Corno de África tem vindo a reduzir desde 20I2, verifica-se um aumento considerável da pirataria, com assalto à mão armada, e outros crimes marítimos na região do GG, onde há um dos maiores campos petrolíferos offshore do mundo, tornando urgente a intervenção dos Estados africanos no combate a este fenómeno (UNODC 20I6).

Na região do GG, os piratas fazem parte do grupo de interessados nas explorações de petróleo e gás natural, tirando proveito do aumento da atividade marítima nesta região, no sentido em que no período entre janeiro de 2014 a dezembro de 2018 , mais de 200 tentativas de ataques a navios foram perpetradas por piratas na costa ocidental do continente Africano (IMB 2020). Assim, percebe-se que nestas regiões a causa potenciadora da pirataria está sempre associada ao vazio de autoridade dos Estados nos espaços marítimos, concretamente por instabilidade política, guerra civil, políticas públicas ineficazes e falta de recursos em terra.

Como resultado, nos últimos anos, os navios transportadores de petróleo têm sido o alvo preferencial, que de acordo com Assis Malaquias (20I2), "Their main targets are oil tankers. They're after the oil. They rob the tankers then transfer the oil to smaller ships, which transfer it again to other ships, until you lose track of it. They're not really after cargo, ships, or anything other than oil". Esta atividade vulgarmente conhecida como "illegal oil bunkering" tem sido também o motor do fenómeno da pirataria na região do GG, especialmente, porque o assalto de petróleo tem sido muito lucrativo para os grupos criminosos, que usam o mercado negro para o escoamento desta carga, favorecidos por uma máfia poderosa transnacional, que financia e facilita as operações piratas; o que faz com que muitas vezes a pirataria seja confundido com o fenómeno do terrorismo (Baldauf 20I2).

5 Embora constituindo uma exceção, em sentido contrário, na margem leste verificou-se um ligeiro aumento dos incidentes com piratas, dentre os quais os sequestros dos navios Aris I3, Asayr 2 e o Al Kausar. Vide: http://oceansbeyondpiracy.org/reports/sop/east-africa. Acesso em: I5 de fevereiro de 2020 . 
De igual modo o "terrorismo marítimo"' que não é facilmente dissociado da pirataria pelo seu caráter complexo e ao mesmo tempo transversal a todas outras manifestações do crime organizado no mar, tem preocupado os Estados africanos. Especialmente, devido a maior dimensão e expressão que alguns movimentos têm adquirido nos últimos anos, tais como o Movimento para a Emancipação do Delta do Níger (MEDN) e o Boko Haram, minando a estabilidade nestes países e contaminando o ambiente sociopolítico regional; porquanto têm-se registado vários atos de terrorismo marítimo, designadamente na indústria petrolífera, resultando em danos nas infraestruturas petrolíferas e prejuízos econômicos e ambientais.

De fato, o terrorismo marítimo é uma ameaça real que tem posto em causa a segurança e a estabilidade do sistema internacional7, sendo que as motivações das organizações terroristas têm sido de cariz variado, sendo os principais alvos as cargas preciosas ou as infraestruturas marítimas, com uso ou não de Armas de Destruição Maciça (ADM) (Ridley 20I4). Na região ocidental do continente Africano, o roubo de carga e o derramamento de crude no mar têm sido as principais manifestações, desta vertente da criminalidade no mar, expressando o potencial negativo que o terrorismo tem relativamente à economia e ao ambiente marinho, sendo lesivo para o ambiente, economia e soberania territorial, na medida em que este fenómeno é particularmente condenado pela "Convenção SUA I988" e pelo seu "Protocolo de 2005".

Assim, os casos da plataforma petrolífera Bonga, atacada a 60 milhas náuticas do Delta do Níger em junho de 2008 pelo MEDN, forçando a paragem nas operações de produção; do desaparecimento do Navio-petroleiro Kerala, de bandeira liberiana, ao serviço da Sociedade Nacional de Combustíveis de Angola, em janeiro de 20I4, com perdas de várias toneladas de gasóleo; ou ainda do Navio-graneleiro MV Bonita, de bandeira norueguesa, abordado

6 O conceito de terrorismo marítimo difere da noção de pirataria marítima, devido a sua natureza, sendo que o fator diferencial encontra-se nas motivações e no objetivos que encerram um e outro fenómeno, isto é, a pirataria é de uma maneira geral motivada por interesses privados, não estando subjacentes objetivos de caráter político-ideológico, enquanto o terrorismo marítimo é percebido como uma das várias formas de rebelião armada, geralmente de caráter político ideológico, visando a provocação-repressão-desestabilização. A pirataria marítima surge assim como um instrumento do terrorismo marítimo, sendo que o terrorismo abrange todas as atividades ilícitas no espaço marítimo, que tenham motivação políticoideológicas (Cottim 2008).

7 O primeiro acontecimento global marcante de terrorismo maritimo, na história internacional recente, aconteceu em outubro de 1985 , onde o navio de cruzeiro italiano Achille Lauro foi sequestrado, no Mediterrâneo, por um grupo de terroristas palestinianos, que criou o terror e assassinou Leon Klinghoffer, um passageiro americano. Este evento deu lugar a criação da "Convenção para a Supressão de Actos Ilícitos contra a Segurança da Navegação Marítima" SUA i988. 
por piratas em novembro de 2019; traduzem o quadro de insurgência dos movimentos terroristas nesta região (Ginga 20I4, IMB 20I9).

Outrossim e na última década, constatou-se um aumento do "narcotráfico" na região subsariana, o que tem contribuído mais ainda para a sua insegurança marítima. Neste quadro, a situação geográfica da África Ocidental, entre a América Latina e a Europa, associada a permeabilidade das suas fronteiras marítimas, torna estes Estados atrativos para essa atividade, no sentido em que a última década "[...] has seen West Africa catapulted to global notoriety for its role as a key transit point in the trafficking of narcotics between Latin America and Europe [...]" (Marc, Verjee e Mogaka 20I5, 33).

Desde 2006, os países da África Ocidental têm estado inseridos nas principais rotas utilizadas para o transporte de cocaína da América do Sul para a Europa, na medida em que têm sido confiscadas grandes quantidades de cocaína, representando apenas uma parcela de um grande volume de negócios, transportadas geralmente através de pequenos navios e jatos privados, destinado aos traficantes dos países da África Ocidental, enquanto epicentro da cocaína no continente (UNODC 20I8). Neste quadro, a costa ocidental, nomeadamente a região do GG, surge como uma zona preferencial de passagem das rotas marítimas das organizações criminosas, num contexto em que a maior parte da cocaína $(60 \%)$ transportada pelo mar, com destino a Europa, passa pelo GG. A região representa hoje um "hub" para o comando e controlo das cargas ilícitas, originárias na maior parte dos países da América Latina, fazendo com que esta atividade apoie as outras variantes do crime organizado na região (MUGRIDGE 20IO).

Consequentemente tem-se observado o aumento dos transbordos do narcotráfico nas águas dos Estados desta região, sendo essas cargas depois transferidas para os países vizinhos, a partir dos quais a maior parte é enviada à Europa e ao Norte de África (UNODC 20I8). Tal como defendeu o antigo Secretário-geral das Nações Unidas, Ban Ki Moon, "drug trafficking does not respect borders [...] the transnational nature of the threat means that no country can face it alone" (UNODC 2009), pelo que a cooperação deficiente entre os Estados a nível regional tem favorecido largamente as redes do crime organizado, na medida em que segundo as estimativas, os transbordos anuais de cocaína na África Ocidental variam largamente entre as 60 e 250 toneladas, com uma receita situada entre os 3-I4 mil milhões de USD anuais.

Assim, tal como a pirataria, o terrorismo e o narcotráfico prejudicam o comércio e tornam o investimento em África mais arriscado e oneroso, a "pesca INN" enfraquece o desenvolvimento econômico, agravando os desafios de segurança alimentar no continente. De acordo com as estimativas, atualmente, um em cada quatro peixes em África é capturado ilegalmente. 
A pesca INN tem posto em causa a sustentabilidade dos estoques de peixes, prejudicando o ecossistema, privando os governos de renda e os povos africanos de seus meios de subsistência ${ }^{8}$, sendo que segundo Peter Thomson, Enviado Especial das Nações Unidas para o Oceano, o flagelo da INN está afetando a maioria das nações africanas, sobretudo porque 38 dos 54 Estados africanos têm fronteiras costeiras e muitos países do interior têm vastos lagos, que também têm sido afetados pela pesca INN e pelas más práticas de pesca (Holmyard 20I8).

Na África Ocidental, as suas práticas custam à região cerca de I.3 mil milhões de USD anualmente, o que tem suscitado cada vez mais à atenção das lideranças africanas para a dimensão do crime, obrigando a que estes tomem atitudes mais proactivas, com vista a fazer face a este crime. A questão da pesca INN em África foi bem estudada e numerosas soluções foram propostas, dentre as quais o relatório de $20 \mathrm{I} 6$ do "Overseas Development Institute" e do grupo espanhol de pesquisa e jornalismo, que usou o rastreamento por satélite para monitorar os métodos e a escala do problema, destacando que os transbordos, a falta de inspeção de cargas em contentores, os diplomas jurídicos inadequados, a tecnologia deficiente e a falta de vontade política, têm sido os principais causadores deste fenómeno. O relatório estimou que, ao desenvolver e proteger a pesca no continente, cerca de 3 mil milhões de USD seriam poupados e mais de 300.000 empregos criados (Holmyard 20I8), num cenário em que de acordo com os dados apresentados pela Comissão Econômica das Nações Unidas para África (United Nations Economic Commission for Africa - UNECA), "[...] around USD 42 billion per year leaves the continent through illegal fishing and illegal logging, among other causes" (UNECA 20I6, 3).

A China é a maior potência pesqueira na África Ocidental, com mais de 500 embarcações de pesca industrial operando nas águas da região, pelo que deve desempenhar um papel maior no que diz respeito à erradicação das práticas ilegais em sua frota, excluindo o uso generalizado de redes com malhas ilegais e a proibição da caça de tubarão, conforme descrevem os relatórios da Greenpeace. Desde 20I6, a China cancelou subsídios no valor de III, 6 milhões de USD, para 264 embarcações que praticavam a pesca ilegal, bem como revogou as licenças de pesca em águas estrangeiras de várias empresas, tendo elaborado uma lista negra de navios e profissionais da área?

8 Estima-se que a pesca INN representa $40 \%$ das capturas anuais da região da África Ocidental, sendo por isso considerada a região onde se regista o mais alto nível de pesca INN (Osinowo 20I5, 2).

9 A China pode ter a maior frota operando em África, todavia não é a única que beneficia da pesca INN. Em 20I7, o grupo de conservação dos oceanos, OCEANA, revelou que alguns 
Paralelamente, existem ainda no continente várias outras manifestações do crime organizado, como a imigração ilegal, o contrabando de pessoas e minerais, o tráfico de armas, o depósito de materiais perigosos, entre outras atividades que fragilizam a segurança marítima, prejudicando o transporte e o comércio marítimo, e motivando uma perturbação crescente no sistema político internacional. Neste ínterim e no que diz respeito ao "tráfico de armas”, observa-se que a questão da proliferação de armas pequenas e leves no GG, nos últimos anos, tornou-se uma grande ameaça à segurança marítima, que deve ser resolvida com urgência, sob pena de se perpetuar a instabilidade sociopolítica na região.

Por sua vez e no que diz respeito à "imigração ilegal e ao tráfico de pessoas", por ou através do mar, tem-se verificado um crescimento deste fenómeno nas águas continentais, constituindo presentemente uma grave ameaça à soberania, concretamente porque põe em causa os direitos humanos. Este fenómeno não pode ser combatido isoladamente, especialmente num contexto local onde se verifica a ineficácia das forças de segurança no mar, tornando-se então necessário que os Estados africanos evoluam as suas doutrinas navais para uma visão marítima mais alargada e partilhada, a fim de em conjunto identificarem os desafios enfrentados e traçarem estratégias de no âmbito da segurança marítima (Baker 20II, 40).

De acordo com alguns observadores das missões de avaliação e de informação do United Nations Office on Drugs and Crime (UNODC), na região do GG, atualmente nenhum Estado da região dispõe de uma combinação entre instrumentos jurídicos de legislação penal e de capacidade formal, suficientes para a penalização contra algumas variantes da criminalidade no mar, concretamente a pirataria e o terrorismo marítimo; o que tem promovido o atraso conjuntural nesses Estados, nas matérias ligadas à construção de capacidades locais, no âmbito da segurança marítima ${ }^{\mathrm{IO}}$, necessárias para contrariar a criminalidade crescente nesta região (UNODC 20I6, 26).

Em suma, a insegurança marítima em África tem representado assim

países europeus, incluindo a Grécia, Itália e Portugal, tinham incentivado a pesca INN ao longo da costa africana, na medida em que em abril de 2018 identificou e rastreou uma embarcação comercial espanhola que desligou seu sistema de localização automática (AIS) enquanto pescava nas águas africanas (Holmyard 2018).

Io O conceito de Segurança atualmente inclui as matérias no âmbito da "security", associadas à proteção contra as ameaças conscientes aos navios, pessoas, insfraestruturas e equipamentos ligados às atividades marítimas, envolvendo instrumentos de força e medidas para proteger a navegação e os recursos do mar e combater a criminalidade nos espaços marítimos; e as matérias relacionadas com a "safety", correspondente à segurança no mar no âmbito da prevenção de acidentes no mar e das ações subsequentes em caso de sinistro, às regras para a condução segura da navegação (Ginga 20I4, 54). 
uma permanente ameaça transnacional à segurança global, porquanto o fator "segurança no mar" é essencial na consolidação do desenvolvimento em terra e que ambos são elementos estratégicos para o desenvolvimento sustentável do continente e para preservação da estabilidade global. Em função disso, nos últimos anos, os Estados africanos têm apostado em promover e preservar a boa ordem no mar, de forma a melhorar a segurança marítima nas suas águas, fomentando assim o desenvolvimento local.

\section{Os Desafios e Instrumentos no Âmbito da Segurança Marìtima}

De acordo com a Fundação Brenthurst Foundation (20I0, IO), a Segurança Marítima numa perspetiva africana deve resultar do conjunto de ações "[...] that creates, sustains or improves the secure use of Africa's waterways and the infrastructure that supports these waterways", particularmente porque a maior parte das ameaças marítimas, sejam elas estruturais ou circunstanciais, se não forem devidamente contrariadas, podem transformar-se em focos de conflitualidade interestadual, pondo em causa à segurança humana e a integridade territorial. Tudo tem sido ampliado, por as fronteiras marítimas serem difíceis de guarnecer, na medida em que as ameaças marítimas não são isoladas, pelo contrário elas reforçam-se mutuamente.

Por isso, seja qual for a forma de manifestação das ameaças, devido a sua magnitude, pelo fato de estarem intimamente interconectadas e de produzirem uma diversidade de impactos, exigem dos Estados africanos uma resposta combinada e contínua das Forças intervenientes nas questões da defesa e segurança marítimas. Isso aplica-se ao nível global, continental, regional e até local, onde as responsabilidades sobre as questões de segurança marítima não devem continuar a ser assunto exclusivo das autoridades governamentais, mas tratadas por todo um conjunto de atores estatais e não estatais, com intervenção direta ou indireta nestas matérias.

Assim, após uma lenta subida na agenda de segurança continental, nos últimos anos, a segurança marítima tem ocupado uma posição central no contexto regional, porquanto existe agora uma consciência crescente sobre as questões da segurança marítima. Por tudo isso e considerando que o DMA tem um elevado potencial para a criação de riqueza e preservação da estabilidade regional, os Estados africanos têm prestado maior atenção aos assuntos relativos ao ambiente marítimo, nomeadamente ao nível da defesa e segurança marítimas, para fazer face aos indices de insegurança nas suas àguas.

Surge assim no continente uma nova noção de fronteira marítima, 
quanto às questões de segurança e defesa, sendo que a atuação dos Estados africanos nos principais Fora de concertação politica sobre os assuntos marítimos tem crescido, mormente porque, hoje, a segurança marítima passou a ser encarada como um pilar central nas políticas de desenvolvimento econômico (Adejumobi e Olukoshi 2008). De forma mais articulada, em 2009, o debate sobre a segurança ${ }^{\mathrm{II}}$ marítima alcança a agenda da UA, por influência de uma série de Resoluções adotadas pelo Conselho de Segurança das Nações Unidas (CSNU), sendo que durante a I5a Sessão Ordinária da Assembleia da UA, em julho de 2009, ficou expressa a preoucupação dos lideres africanos com a crescente insegurança nos espaços marítimos africanos de forma geral, e da Somália em particular (UA 2009a).

No seu seguimento, o Departamento de Infraestrutuas e Energia da UA organizou a 2a Conferência dos Ministros dos Transportes da União Africana, entre I2-I6 de outubro do mesmo ano, tendo sido adotada a "Durban Resolution on Maritime Safety, Maritime Security and Protection of the marine environment in Africa", que vem reafirmar o compromisso dos Estados-membros com a CNUDM; com as iniciativas conduzidas pela OMI e pelo CSNU; com as suas responsabilidades no âmbito da segurança marítima; com a intensificação das dinâmicas de coordenação em busca de respostas conjuntas para fazer face ao flagelo da pirataria e insegurança marítimas; com a criação de uma rede regional para apoiar no combate à criminalidade marítima, entre outros (UA 2009b).

Consciente de que a pirataria marítima, o assalto à mão armada e outras atividades ilícitas, constituem uma séria ameaças ao domínio marítimo da África Central e Ocidental, o CSNU, através das "Resoluções” 20 I8 (20II) e 2039 (20I2), exortou os Estados das comunidades econômicas regionais (CEEAC - Comunidade Econômica dos Estados da África Central; e CEDEAO - Comunidade Econômica dos Estados da África Ocidental) e da região do GG a tomarem medidas imediatas a nível local e regional, conducentes a implementação de um quadro legal e doutrinário para fazer face à insegurança marítima.

Como resultado, entre $24-25$ de junho de 2013 , em Yaoundé, deu-se a "Cimeira de Chefes de Estados e de Governo sobre a proteção marítima e

II Este debate em torno da segurança marítima em África foi apadrinhado pelas Nações Unidas e pela Organização Marítima Internacional (OMI), sendo que em I4 janeiro de 2009 foi estabelecido o "Contact Group on Piracy off the Coast of Somalia" (Grupo de Contato sobre Pirataria ao largo da Costa da Somália), em obediência à Resolução I85I (2008) do CSNU. A OMI organizou o encontro entre I6 Estados árabes e africanos em Djibuti em 26 de janeiro de 2009, que adotou um Código de conduta relativo a repressão à pirataria e roubo à mão armada contra navios, no Oceano Índico Ocidental e o GA - "Código de conduta de Djibuti - CCD" (IMO 2009). 
segurança no Golfo da Guiné”, onde foram aprovados três diplomas no âmbito da segurança marítima, a saber: o "Código de conduta sobre a repressão da pirataria, assalto à mão armado contra navios, e atividade marítima ilícita na África Ocidental e Central" (Código de Conduta de Yaoundé - CCY); a "Declaração dos Chefes de Estado e de Governo dos Estados da África Central e Ocidental" para a segurança marítima e segurança no seu domínio marítimo comum; e o "Memorando de Entendimento" (MdE) entre a CEEAC, CEDEAO e a CGG, sobre a segurança marítima na África Central e Ocidental - ligados à proteção e segurança marítima na África Central e Ocidental, e região do $\mathrm{GG}^{12}$.

Neste quadro, a Declaração de Chefes de Estado e de Governo dos Estados da África Central e Ocidental sobre Segurança Marítima no seu Domínio Marítimo Comum de 2013, representa o principal instrumento sufragado deste encontro e um documento pioneiro de cooperação e partilha de informação ao nível da segurança marítima, porquanto manifesta o reconhecimento que os Estados têm vindo a atribuir às questões relativas à segurança no mar. Ao nível nacional, o foco será a coordenação interministerial, os mecanismos de cooperação entre as instituições do Estado e parceiros do setor privado e a preparação de respostas para contrariar a insegurança no mar. Ao nível regional, esta reunião determinou a criação do do conhecido CCY.

Mais tarde, em 5 de junho de 20I4, os três organismos assinaram o Protocolo adicional ao MdE entre a CEEAC, CEDEAO e a CGG, que estabelece a criação do Interregional Coordination Center (ICC), tendo sido inaugurado em setembro do mesmo ano em Yaoundé (ICC 20I4). O ICC é um instrumento a nivel estratégico de cooperação, coordenação e comunicação entre os Estados-membros das três organizações, incluindo a partilha de informações, o desenvolvimento de boas práticas e a capacitação na prevenção e combate da pirataria, assalto à mão armado e outras atividades ilícitas no mar. Os 24 Estados signatários do CCY estão agrupados em 5 zonas marítimas, sendo cada uma apoiada por centros de coordenação regional, isto é, uma para a CEDEAO (CREMAO - Centro Regional de Segurança Marítima da África Ocidental) e outra para a CEEAC (CRESMAC - Centro Regional de Segurança Marítima da África Central), sendo coordenados por um Centro de Coordenação Inter-

I2 No que toca à edificação de uma arquitetura para a segurança marítima regional, a CEEAC foi a primeira a adotar um instrumento conducente a esta visão, através do Protocolo que criou a Estratégia Integrada para a Segurança Marítima (EISM), em 2009; seguida pela CGG que adotou a Io de agosto de 2013 uma Estratégia Marítima Integrada da região, e por último pela CEDEAO que aprovou a Estratégia Marítima Integrada da região em março de 20 I4 (ICC 20I7). 
Regional (ICC), que é supervisionado pelas três organizações regionais (ICC 20I7).

O CCY e o ICC, no quadro Estratégia da OMI para reforçar a proteção marítima em África, surgem como uma continuidade ao CCD e um complemento à "Emenda de Jeddah" 13 de 2017 , que introduz ao código outras modalidades da criminalidade maritima no Oceano Indico e Golfo do Adem a combater, sendo que de acordo com o almirante Adejimi Osinowo "o principal valor desta iniciativa reside na partilha de informações e no estabelecimento dos protocolos de autorização necessários para perseguir navios suspeitos através das fronteiras marítimas" $(2015,4)$. De fato, nenhuma região no continente assistiu a um crescimento mais rápido e extenso na arquitetura da segurança marítima ao longo dos últimos anos como a região do GG, com um conjunto de instrumentos e instituições, fazendo com que a Arquitetura de Yaoundé para a Segurança e Proteção Marítimas (Yaounde Architecture Maritime Safety and Security - YAMSS) constitua uma história de sucesso, a nível continental.

Paralelamente, em respeito à sua Resolução A.Io69(28) (20I4), a OMI desenvolveu e implementou um programa de "tabletop exercises" para o GG, destinado a promover uma abordagem inter-estadual para proteção marítima e aplicação da lei do mar na África Ocidental e Central. Este programa visa manifestar a necessidade de cooperação entre os departamentos governamentais e agências locais, através de cenários prováveis e simulados, de forma a determinar os mehores métodos, processos e procedimentos, para a operacionalização de uma estratégia maritima conjunta na região (Araújo 20I5).

Este quadro surge em convergência com a necessidade de os Estados africanos implementarem uma verdadeira arquitetura de segurança marítima africana, como defende a "Estratégia Africana Integrada para os Mares e os Oceanos 2050"14 (Estratégia AIM 2050). A AIM 2050 foi desenvolvida como

I3 Em contraste ao CCD, que centra-se principalmente à pirataria, o CCY contém uma abordagem abrangente de segurança marítima regional, visando combater não apenas a pirataria e o assalto à mão armada contra navios, mas todas outras manifestações da criminalidade no mar, tornando-a muito mais ampla no seu alcance. A "Emenda ao CCD" constitui um acordo não-vinculativo entre 2I países da África Oriental, surgindo como um Código de conduta revisto, referente à repressão da pirataria, assalto armado contra navios e a outras manifestações da criminalidade marítima no Oceano Índico ocidental e na região do GA. O acordo baseia-se em 4 grandes pilares (formação regional; revisão do quadro legal local e regional; partilha de informação e construção de capacidade local), com o objetivo de reforçar a cooperação e coordenação regional e desenvolver a formação e capacidade necessária para que as autoridades locais assumam o seu papel no combate à criminalidade no mar (Araújo 20I5). I4 Nascida na I3a Sessão Ordinária da Conferência da UA, realizada em Sirte, em julho 
uma ferramenta para enfrentar os desafios marítimos em África, em ordem a criar riqueza a partir dos oceanos, mares e vias navegáveis interiores de África, através do desenvolvimento de uma economia marítima próspera e da exploração de todo o potencial das atividades marítimas de uma forma ambientalmente sustentável (UA 20I2).

Outrossim, a "Carta da União Africana sobre a Proteção e a Segurança Marítimas e o Desenvolvimento em África” (Carta de Lomé), adotada na Cimeira Extraordinária da União Africana a I5 de outubro de 20I6, em Lomé, surge também como um instrumento importante, no leque das iniciativas locais que destinam-se a contrariar o dilema da insegurança marítima no continente. A Carta de Lomé visa fazer do espaço marítimo o catalisador principal do desenvolvimento socioeconômico de África, reforçando a necessidade de implementar o $\mathrm{MdE}^{\mathrm{Is}}$, assinado em julho de 2008 , entre a OMI e a OMAOC (Organização Marítima da Africa Ocidental e Central), no quadro da IMO's Integrated Technical Cooperation Programme (ITCP); para estabelecer uma Rede integrada de guarda costeira sub-regional na África Ocidental e Central, e o respetivo quadro de cooperação e orientação para a implementação desta rede integrada (OMAOC 2008, Chatham House 20I2, I6).

No que toca à pesca INN e de acordo com a organização "Stop Illegal Fishing”, uma organização independente, sem fins lucrativos com sede em África, dedicada a erradicar com a pesca ilegal nas águas do continente, os Estados africanos têm desenvolvidos esforços para refrear com o fenómeno da pesca INN, todavia o fenómeno carece de uma nova abordagem por parte destes. Neste ínterim, o "Africa's Blue Economy: a policy handbook" (Manual sobre políticas para uma Economia Azul Africana) apresenta um conjunto de linhas de ação para mitigar a pesca INN, além de combater a poluição marinha e a pirataria, perspetivando um crescimento econômico rápido e diversificado no continente ${ }^{\mathrm{I} 6}$ (UNECA 20I6).

de 2009, formalizada em 20I2, e adotada a 3I de janeiro de 2014 em Adis-Abeba. A OMI participou ativamente em colaboração com a UA no desenvolvimento da Estratégia AIM 2050, estando a mesma sediada no continente, através de três escritórios regionais, localizados em Abidjan (Costa do Marfim), Acra (Gana) e Nairobi (Quênia), com base em MdE assinados entre a OMI e os Estados anfitriões. Vide: http://www.imo.org/en/OurWork/TechnicalCooperation/ GeographicalCoverage/Africa/Pages/Default.aspx. Acesso em I4 de janeiro de 2020.

I5 Assinado por I6 dos seus 20 Estados-membros costeiros, o MdE visou empreender esforços conjunturais no domínio marítimo, com vista a proteger a vida humana, fazer cumprir a lei no mar, contrariar as atividades criminosas no mar, melhorar a segurança marítima e proteger os recursos do mar.

I6 Nos últimos anos, a UNECA começou a fornecer mais apoio local, nacional e regional para apoiar o desenvolvimento da "Economia Azul" africana, trabalhando com outros parceiros 
Paralelamente, o "Centro de Partilha de Informação sobre o Comércio Marítimo do Golfo da Guiné" (MTISC GoG - Maritime Trade Information Sharing Centre GulfofGuinea), estabelecido pelo Fórum Marítimo Internacional das Empresas de Petróleo como um projeto-piloto, entrou em operação em outubro de 20I4, tendo sido sediado na Universidade Marítima Regional de Acra, no Gana. O MTISC GoG tinha como meta principal, o estabelecimento de um centro regional de partilha de informações marítimas na região. Em I5 de junho de 20I6, o MTISC-GoG encerrou após o projeto-piloto ter sido bemsucedido. Em resposta, as autoridades francesas e britânicas, apoiando-se na experiência alcançada com o MTISC-GoG, lançaram um novo contributo para a rede de partilha de informação marítima no GG, através de um centro virtual de informação.

O novo centro França-Reino Unido, denominado Marine Domain Awareness for Trade - Golf of Guinea ${ }^{\text {I7 }}$ (MDAT-GoG), iniciou suas operações em junho de 20I6, reforçando a capacidade dos Estados da região ao nível do Maritime Domain Awareness ${ }^{18}$ (MDA), servindo de uma plataforma por excelência de partilha de dados, informação e conhecimento, entre os Estados da região, porquanto destina-se a fornecer um panorama detalhado do domínio marítimo das águas na região da África Ocidental'19. Esta iniciativa associou-

internacionais, incluindo a UA, o Programa das Nações Unidas para o Meio Ambiente (PNUMA) e o Banco Africano de Desenvolvimento (BAD), que têm a Economia Azul na vanguarda das suas prioridades econômicas para o continente.

I7 Além de oferecer assessoria operacional e consciência situacional aos navios mercantes na região, reduzindo o risco de sofrerem ataques dos grupos da criminalidade organizada, a equipa multinacional de vigilância do MTISC-GoG também fornecia apoio aos capitães dos navios e armadores que tivessem sido vítimas de atos criminosos. O MDAT-GoG é atualmente operado remotamente pelas marinhas da França e do Reino Unido, a partir de centros localizados em Brest (França) e Portsmouth (Reino Unido). Vide: http://www.imo.org/en/OurWork/Security/ WestAfrica/Pages/Code-of-Conduct-against-illicit-maritime-activity.aspx. Acesso em I3 de fevereiro de 2020 .

I8 O conceito de "Maritime Domain Awareness" (Consciência do Domínio Marítimo) tem origem na doutrina norte-americana do "U.S Homeland Security Department", que numa melhor tradução significa "Consciência Situacional do Dominio Marítimo", que traduz um conhecimento continuado e regular sobre o ambiente marítimo, da região em referência. O seu principal objetivo é o de reunir o máximo de informações sobre qualquer navio ou embarcação, numa determinada região; e análisá-las com apoio a um conjunto de meios e recursos de "inteligência” (maritime intelligence), de forma permitir “ a compreensão efetiva de qualquer questão associada ao domínio marítimo que pode impactar a segurança, proteção, economia ou meio ambiente" (U.S HSD 2005, ii).

I9 O MDAT-GoG administra um esquema de tráfego com uma Área de Notificação Voluntária (Voluntary Reporting Area - VRA), com rotas e pontos de relatório voluntário, pelo que os navios mercantes são encorajados a seguir este esquema enquanto circulam nesta região. Em novembro de 20I9, o Navio "NRP Zaire" da Marinha Portuguesa cumpriu uma missão de acompanhamento do navio mercante "Maersk Tema", que transitava ao largo das àguas da 
se ao programa criado pela União Europeia, "the European Union supports the Critical Maritime Routes Programme", e implementado em 40 Estados, dentre os quais nos países da região do GG através do CRIMGO (Critical Maritime Routes Gulf of Guinea), durante o período de $2013-2016^{20}$.

Localmente, reconhecendo que a história da segurança marítima e da proteção do ambiente marinho na sub-região da África Ocidental está repleta de incidentes que expõem a falta de capacidade e de resposta local, o terrorismo marítimo e a pirataria surgem como os principais critérios de avaliação do contexto de insegurança, no sentido em que os Estados continuam a melhorar as suas capacidades de fiscalização e vigilância, quer através da aquisição de novos meios navais, como mediante a implementação de mais exercícios cominados entre as diferentes Forças no âmbito da segurança e defesa marítimas.

Entender as fragilidades marítimas dos Estados africanos permite combater a criminalidade nos espaços marítimos, especialmente porque a quantificação dos custos econômicos, humanos e ambientais, é fundmental para compreender o verdadeiro impacto da criminalidade no mar. Assim e de acordo com o relatório apresentado pela plataforma "Oceans Beyond Piracy", no ano de 20I7, o custo econômico total para contrariar os atos de terrorismo e pirataria, na região da África Ocidental, ascendeu os 8I8 milhões de USD ${ }^{21}$. Em vista disso, nos últimos anos, verifica-se um aumento na ordem dos $27 \%$ na taxa de resposta aos incidentes de ataque pelas forças de segurança marítima (Steffen 20I6).

Em suma, nos últimos anos, mesmo que de forma pouco ordeira, os Estados africanos têm aprofundado os laços de partilha e cooperação, com vista a melhorar a segurança marítima nas suas águas e garantir a sustentabilidade na exploração dos recursos marinhos nestes espaços; na medida em que infere-se que a criação de capacidade ao nível da proteção e segurança maríti mas, para fazer face aos desafios, deve ser uma prioridade continua e abrangente.

Portanto, são várias as manifestações deste maior interesse dos Estados da regiãoo pelas questões quee envolvem a segurança maritima, sendo que importa realçar: o "MdE operacional" entre as guardas costeiras da Nigéria e do Benin, que visa o patrulhamento das águas para combater o crime

República de São Tomé e Principe, na sequência de um alerta de ataque de pirataria feito através do MDAT-GoG. Vide: https://www.noticiasdecoimbra.pt/marinha-portuguesa-procurapiratas-no-golfo-da-guine/. Acesso em ig de fevereiro de 2020.

20 Vide: https://criticalmaritimeroutes.eu/projects/crimgo/. Acesso em I6 de março de 2020. 2 I Vide: http://oceansbeyondpiracy.org/reports/sop/west-africa. Acesso em 23 de março de 2020. 
organizado nas àguas da região; o Exercício militar de interdição marítima "Obangame Express", com a participação de várias forças navais; a cooperação entre as marinhas da África do Sul, Namíbia e Moçambique; a "Convenção da Corrente de Benguela", um acordo tripartida entre as Repúblicas de Angola, Namíbia e da África do Sul, para promover uma abordagem regional coordenada para a proteção do grande ecossistema marinho da Corrente de Benguela; entre outras iniciativas de caráter local, regional e internacional.

\section{Uma visão prospetiva para o continente Africano}

A alteração do quadro geopolítico mundial obriga os Estados africanos a encararem com maior seriedade às questões relacionadas à insegurança marítima, tendo em vista a defesa dos interesses nacionais e a promoção do desenvolvimento econômico. Na verdade, começa a existir a consciência de que, a paz e estabilidade política em África resultará essencialmente do incremento da segurança humana, sendo que a mesma não se garante apenas pelo "somatório da segurança de cada Estado", mas pelo conjunto de sinergias movidas entre Estados e Organizações Regionais Africanas (ORA), visto que estas últimas constituem-se num elo privilegiado entre as Organizações Internacionais e os Estados não-africanos cooperantes, alargando a perspetiva bimultilateral da cooperação para as questões de segurança e defesa, na região.

Portanto, hoje, as relações de cooperação transfronteiriça constituem o mais elevado expoente da atuação política no seio das regiões, pelo que as ORA devem continuar a servir de plataforma para a implementação das dinâmicas de cooperação multilateral e os convénios de cooperação bimultilateral existentes. Neste domínio, tal como em terra, nos oceanos, as ORA devem constituir a base de manutenção da "Nova Ordem Africana", devendo partilhar com os Estados a responsabilidade sobre os destinos do continente, designadamente nas questões de segurança marítima; independentemente da arquitetura de segurança marítima no continente (Vines 2013, 93).

Neste quadrante, entende-se que no nível "doméstico" deve existir uma maior partilha de responsabilidades entre os vários atores que, direta ou indiretamente, têm intervenção nos assuntos marítimos, mormente porque os oceanos são, por natureza e dimensão, espaços de cooperação multidimensional, de partilha e de utilização coletiva. Exige-se assim a implementação de instrumentos de gestão e de utilização adequadas à multiplicidade de atividades relacionadas com os espaços marítimos, não apenas pela diversidade de intervenientes que por aí operam, mas porque o 
reforço da segurança no mar depende mais de uma gestão estratégica ${ }^{22}$ deste espaço, do que do constante empenhamento de Forças navais (Osinowo 20I5).

Ao nível regional, esta gestão estratégica deverá ser conduzida sob duas perspetivas. A primeira ligada ao "software do sistema", ou seja, a implementação e viabilização de um conjunto de instrumentos do quadro legal e doutrinário, onde se destaca a harmonização da legislação local dos vários Estados da região, a adequação às convenções e protocolos internacionais, acordos e protocolos bimultilaterais no âmbito da proteção, fiscalização, segurança e defesa marítimas, ente outros instrumentos. A segunda relacionada ao "hardware do sistema", correspondente aos recursos físicos e infraestruturais, necessários para a consolidação de qualquer modelo de governação integrada dos espaços marítimos, onde se incluem os meios necessários para o controlo e monitorização permanente do espaço marítimo da região, isto é, os meios navais, os sistema de balizagem, os sistemas de radares em terra (Vessell Traffic Service - VTS), os centros de coordenação de informação e operações marítimas, entre outros recursos que reforçam a capacidade regional a nível do Maritime Domain Awereness.

Outrossim, para garantir a segurança marítima e a desejada interoperabilidade de Forças no mar, é essencial que os Estados africanos continuem a operar em rede, de forma a garantir a complementaridade entre os meios disponíveis na região, com tripulações treinadas e um sistema de apoio em terra, que garantam o exercício permanente da autoridade do Estado no mar (Mcnicholas 20II). Trata-se, portanto, de promover iniciativas regionais e continentais para fortalecer as capacidades marítimas locais, bem como harmonizar os regulamentos e legislação local ${ }^{23}$, numa perspetiva de partilha de experiências e informações, no quadro da proteção, defesa e segurança marítimas.

Muito ainda há por ser feito, pelo que a vontade política e o desejo de cooperar por parte dos Estados africanos surgirão como fatores decisivos, essencialmente porque as ações desenvolvidas pelos Estados, isoladamente, são insuficientes, a médio e longo prazos, para combater as redes do crime organizado, num contexto em que a criminalidade no mar resulta de uma ação

22 Os Estados africanos, de forma geral, devem definir e identificar corredores de navegação seguras, com ancoradouros, zonas de boias de amarração de navios, entre outros pontos essenciais, para proteger o comércio marítimo que circula dentro das suas águas territoriais e ZEE, como uma reprodução e extensão do modelo implementado pelas marinhas da França e do Reino Unido, o MDAT-GoG, que definiu um "Corredor de Tráfego Internacionalmente Recomendado" na região da África Ocidental.

23 Uma questão central tem sido a falta de julgamento e condenação dos piratas e outros envolvidos na criminalidade marítima, como consequência da ausência de legislação interna necessária para a criminalização das atividades ilícitas no mar (Osinowo 20I5). 
concertada entre as comunidades criminosas locais, associados a entidades locais, e financiados por redes da criminalidade transnacional organizada.

\section{Considerações Finais}

Na perspetiva de realçar as principais linhas de pensamento traçadas ao longo deste artigo cientifico sobre a conjuntura marítima Africana, onde se provou que a insegurança marítima no continente tem fortes impactos econmicos para os seus Estados, porquanto a sua estrutura econômica encontra-se fortemente dependente da exploração dos recursos marítimos e do comércio marítimo. A insegurança marítima permitiu o florescimento de atividades ilicitas para dentro das fronteiras dos Estados africanos, que somadas aos problemas de instabilidade interna, têm resultado no surgimento de Estados falhados no continente.

$\mathrm{Na}$ realidade, o "domínio marítimo africano" tem sido uma fonte de insegurança regional, afectando a estabilidade continental. A pirataria, o terrorismo marítimo, o narcotráfico, a pesca INN, a imigração ilegal, o contrabando de armas e outras ameaças que se desenvolvem nas águas africanas, têm prejudicado o exercício da autoridade do Estado e impactando negativamente na economia continental, porquanto para os Estados costeiros não haverá desenvolvimento econômico sustentável sem que se garantam niveis minimos de segurança marítima.

Abordar a insegurança marítima em África significa reportar sobretudo o atual contexto, onde os Estado africanos atribuem maior importância às questões inerentes a segurança marítima, na medida em que, nos últimos anos, tem-se verificado uma maior preocupação por parte desses Estados com as questões ligadas à segurança marítima no continente. Embora haja algum progresso no tocante à forma de abordar a questão da insegurança marítima, a escassez em termos de recursos tem afetado a implementação das principais Estratégias de segurança marítima, traçadas no quadro local, regional e continental. De fato, tanto os esforços de segurança marítima como o desenvolvimento de uma governança corporativa dos assuntos marítimos têm sido dificultados pela falta de capacidade dos Estados africanos.

Portanto, considera-se que os Estados e as ORA precisam melhorar a sua abordagem integrada e coordenada relativamente aos assuntos marítimos, porquanto devem adequar as suas agendas de segurança para mitigar as principais ameaças à segurança marítima continental, porque, em larga escala, permitirá uma melhor exploração dos benefícios e das oportunidades econômicas dos oceanos. Especialmente, porque o futuro 
continental, tanto em termos de oportunidades como de desafios, encontra-se associado aos mares e oceanos, porquanto o vasto domínio marítimo africano contém inúmeros recursos que, se sustentavelmente explorados, fornecerão, às gerações africanas, recursos significativos para fortalecer os seus esforços contínuos de crescimento e desenvolvimento.

\section{REFERÊNCIAS}

Abegunrin, Olayiwola. 2009. African in Global Politics in the Twenty-First Century. Nova Iorque: Palgrave Macmillan.

Adejumobi, Said \& Olukoshi, Adebayo. 2008. The African Union and New Strategies for Development in Africa. Nova Iorque: Cambria Press.

Almeida, Políbio de. I994. Ensaios de Geopolítica. Lisboa: ISCSP / IICT.

American One Earth Future Foundation [AOEFF]. 20I8. The State of Maritime Piracy 20I7. Broomfield: AOEFF/ Oceans Beyond Piracy.

Araújo, Gisela. 20I5. Atuação da IMO para o desenvolvimento de medidas de Proteção Marítima. Rio de Janeiro: IMO.

Baldauf, Scott. 20I2. "Next pirate hot Spot: The Gulf of Guinea". The Christian Science Monitor. Acesso em 6 mar. 2020: <http://www.csmonitor.com/World/Africa/2012/0228/Next-pirate-hot-spot-the-Gulf-ofGuinea>.

Baker, Michael. 20Iı. "Toward an African Maritime Economy. Empowering the African Union to Revolutionize the African Maritime Sector". Naval War College Review 64 (2): 39-62.

Beny, Eduardo. 2007. A Nova Geopolítica do Petróleo: do Golfo Pérsico ao Golfo da Guiné. Lisboa: Novo Imbondeiro.

Brenthurst Foundation. 2010. Maritime Development in Africa. An Independent Specialists Framework. Joanesburgo: The Brenthurst Foundation.

Castro, Therezinha de. I999. Geopolítica: principio, meios e fins. Rio de Janeiro: Biblioteca do Exército.

Chatham House. 20I2. "Angola e o Golfo da Guiné. Rumo a uma Estratégia Marítima Integrada”. Relatório da Conferência do Angola Fórum a bordo do HMS Dauntless a 29 de junho em Luanda. Londres: Royal Institute of International Affairs.

Coudenhove-Kalergi, Count. I959. From War to Peace .Trad. C. Fitzgibbon. Londres: Jonathan Cape.

Coker, Christopher. 2007. "Strangers at the gate: Africa, the challenge of China and the eclipse of the West". In: Estratégia e Segurança na África Austral, Coord. M Franco. Lisboa: Fundação Luso - Americana.

Cottim, Armando. 2008. "Terrorismo no Mar de um Mundo Globalizado". 
Nação e Defesa 3 (I20): I27-I43.

Duarte, António. 20II. "As Fronteiras Marítimas, a Segurança e a Cooperação Internacional". Maria Scientia - Revista Científica Electrónica Scientific e-Journal I (I): 2-34.

Ginga, Damião. 20I4. "Angola e a Complementaridade do Mar: O mar enquanto fator geoestratégico de segurança, defesa e de afirmação". Tese de doutoramento. Lisboa: Universidade Lusófona de Humanidades e Tecnologias de Lisboa.

Holmyard, Nicki. 2018. "African countries fighting back against illegal fishing", Sea Food Source. Acesso 20 Jun. 2020: <https://www.seafoodsource.com/news/environment-sustainability/african-countries-fighting-back-against-illegal-fishing>.

ICC. 20I4. Protocolo adicional ao memorando de entendimento entre a Comunidade Econômica dos Estados da África Central (CEEAC), Comunidade Econômica dos Estados da África Ocidental (CEDEAO) e a Comissão do Golfo da Guiné (GGC) sobre segurança marítima e segurança na África Central e ocidental do espaço marítimo. Yaoundé: ICC.

ICC. 20I7. Presentation to the Interregional Coordination Center for the execution of the regional strategy on maritime safety and security in the Gulf of Guinea. Yaoundé: ICC.

IMB. 20I9. Piracy and Armed Robbery Against Ships, Report for the Period I January - 3I December 20I8. London: IMB.

IMB. 2020. Piracy and Armed Robbery Against Ships, Report for the Period I January - 3I December 2019. London: IMB.

IMO. 2009. Code of Conduct Concerning the Repression of Piracy and Armed Robbery Against Ships in the Western Indian Ocean and the Gulf of Aden. Djibuti: IMO.

Keohane, Robert. 2002. Power and Governance in a Partially Globalized World. Nova Iorque: Routledge.

Malaquias, Assis. 20I2. "Ask the Expert: The Growing Threat of Oil Pirates in West Africa's Gulf of Guinea". Africa Center for Strategic Studies. Acesso em Io jul. 2020: <http://africacenter.org/2012/03/ask-theexpert-the-growing-threat-of-oil-pirates-in-westafrica\%E2\%80\%99sgulf-of-guinea/>.

Marc, A, Verjee, N e Mogaka, S. 20I5. The Challenge of Stability and Security in West Africa. Washington: Banco Mundial.

Mcnicholas, Michael. 20II. Maritime Security: An Introduction Butterworth-Heinemann homeland security series. Oxonia: Butterworth-Heinemann.

Miah, Seth. 2012. "Pirates on the Gulf of Guinea". Modern Ghana News. Acesso em 22 mar. 2020: <http://www.modernghana.com/news/427026/I/ 
A Insegurança Marítima na África Subsariana e os seus Reflexos na Economia dos Estados

pirates-on-the-gulf-of-guinea.html>.

Mugridge, David. 20I0. "Piracy Storm Brews in West Africa: Gulf of Guinea Under Maritime Siege”. Defence IQ. Acesso em I8 abr. 2020: <http:// www.defenceiq.com/naval-and-maritime-defence/articles/piracystorm-brews-in-west-africa-gulf-of-guinea-u/>.

OMAOC. 2008. Memorandum of Understanding on the Establishment of a Sub-Regional Integrated Coast Guard Network in West and Central Africa. Abidjan: OMI/OMAOC.

Onuoha, Fredom. 2012. Piracy and Maritime Security in the Gulf of Guinea: Nigeria as a Microcosm. Doha: Al Jazeera Center for Studies.

Osinowo, Adeniyi. 20I5. "O Combate À Pirataria no Golfo da Guiné". Africa Security Brief (30): I-9.

Otto, Lisa (Eds.). 2020. "Global Challenges in Maritime Security: An Introduction". Advanced Sciences and Technologies for Security Application. Gewerbestrass: Springer International Publishing AG.

Ridley, Nick. 20I4. Terrorism in East and West Africa: The Under-focused Dimension. Cheltenham: Edward Elgar Publishing.

Steffen, Dirk. 20I6. "West African Navies Coming Of Age?". Center for International Maritime Security Home Page. Acesso em 4 mar. 2020: <http:// cimsec.org/coming-of-age-of-the-west-african-navies/22919>.

União Africana [UA]. 2009a. Report of the Chairperson on the Activities of the Commission Covering the Period January to June 2009. Fifteenth Ordinary Session of the AU Executive Council, Sirte, 24-30 June. Sirte: UA.

UA. 2009 b. Durban Resolution on Maritime Safety, Maritime Security and Protection of the marine environment in Africa. Durban: UA.

UA. 20I2. Estratégia Marítima Integrada de África 2050. Addis Abeba: UA.

UA. 20I3. 2050 Africa's Integrated Maritime Strategy. Summit Of Heads of State and Government of ECCAS, ECOWAS and GGC. Adis Abeba: UA.

UA. 20I6. Carta da União Africana sobre a Proteção e a Segurança Marítimas e o Desenvolvimento em África (Carta de Lomé). Adis Abeba: UA.

United Nations Economic Commission for Africa [UNECA]. 20I6. To order copies of Africa's Blue Economy: A policy handbook by the Economic Commission for Africa. Adis Abeba: UNECA.

UNODC. 2009. "Security Council Debates Devastating impact of Drug Trafficking”. UNODC Home Page. Acesso em I8 jan 2020: <http://www. unodc.org/unodc/en/frontpage/2009/December/security-council-debates-devastating-impact-of-drug-trafficking.html>.

UNODC. 20I6. Programa Regional para a África Ocidental 2016-2020. Nova Iorque: Escritório Regional para a África Central e Ocidental. 
UNODC. 20I6. World Drug Report 2018: Executive Summary. Conclusions and Policy Implications. Viena: Nações Unidas.

U.S. Homeland Security Department [U.S. HSD]. 2005. "The National Plan to Achieve Maritime Domain Awareness". For the National Strategy for Maritime Security. Washington: U.S HSD.

Usoigwe, Godfrey. 20I0. "Partilha europeia e a conquista da África: apanhado geral”. In: História geral da África VII: África sob dominação colonial, 1880-1935. 2nd Ed. Rev., Ed. A. Boahen, 2I-5O. Brasília: UNESCO.

Vines, Alex. 2013. "A decade of African Peace and Security Architecture". International Affairs 89 (I): 89-Io9.

Vogel, Augustus. 2009. "Navies versus Coast Guards: Defining the Roles of African Maritime Security Forces”. Africa Security Brief (2): I-7.

\section{RESUMO}

Parece claro que as lideranças africanas não têm noção da dimensão marítima dos seus Estados, o que tem originado numa subalternização dos assuntos marítimos comparativamente às questões terrestres, na medida em que torna-se essencial que os Estados africanos comecem a dar passos concretos para que se estabeleça, no continente, uma verdadeira arquitetura de segurança e defesa marítimas, tendo como fim o melhor aproveitamento das oportunidades oferecidas pelos oceanos, em nome dos interesses desses Estados. A abordagem foi possível, com recurso a uma revisão bibliográfica e documental, através de uma metodologia qualitativa, seguindo um raciocínio dedutivo.

\section{PALAVRAS-CHAVE}

África; Oceanos; insegurança marítima.

Recebido em 21 de outubro de 2020 Aprovado em 16 de novembro de 2020 